\title{
Possibly Worse
}

National Cancer Institute

\section{Source}

National Cancer Institute. Possibly Worse. NCI Thesaurus. Code C53561.

Showing signs suggestive of deterioration or decline. 